\title{
Human thrombopoietin structure-function relationships: identification of functionally important residues
}

\author{
Alexandre JAGERSCHMIDT*, Valérie FLEURY $\uparrow$, Marielle ANGER-LEROY $\dagger^{-1}$, Corinne THOMAS ${ }^{\star}$, Magali AGNEL* and \\ Donogh Paul O'BRIEN†'² \\ *Synthélabo Recherche, Department of Genomic Biology, 10 rue des Carrières, 92500 Rueil-Malmaison, France, and †Synthélabo Recherche, Cardiovascular Department, \\ 31 avenue Paul-Vaillant Couturier, 92225 Bagneux Cedex, France
}

\begin{abstract}
Thrombopoietin (TPO) is a haematopoietic growth factor responsible for megakaryocyte progenitor proliferation and differentiation. It belongs to the four-helix-bundle cytokine family and exerts its biological effects through binding to a specific receptor, c-Mpl. With the use of site-directed mutagenesis we have generated 20 TPO mutants. Each of the TPO mutants was produced in a eukaryotic expression system and the mutants' ability to induce the proliferation of factor-dependent c-Mplexpressing megakaryoblastic M-O7e cells was compared with that of wild-type TPO. Among the mutations studied, 10 lead to a significant decrease in TPO bioactivity. Of these ten residues, three are located in helix A of the protein $\left(\mathrm{Arg}^{10}, \mathrm{Lys}^{14}\right.$ and $\operatorname{Arg}^{17}$ ) and four in helix D (His ${ }^{133}, \mathrm{Gln}^{132}$, Lys ${ }^{138}$ and $\mathrm{Phe}^{141}$ ),
\end{abstract}

indicating that in TPO, as in other cytokines, these two helices are important for functional cytokine/receptor interactions. Surprisingly, mutant $\mathrm{Arg}^{10} \rightarrow$ Ala (R10A) lacked any proliferative activity, despite the fact that this mutation was recently reported to have no effect on TPO/c-Mpl binding in a TPO phage ELISA [Pearce, Potts, Presta, Bald, Fendly and Wells (1997) J. Biol. Chem. 272, 20595-20602]. The lack of M-O7e proliferation is probably due to an inability of R10A mutant to promote receptor dimerization and thus receptor activation. Moreover we found that the $\operatorname{Arg}^{10}$ and $\operatorname{Arg}^{17}$ residues of TPO seem to be specific determinants for TPO/c-Mpl recognition. We also demonstrate that the $\mathrm{O}$-glycosylation site located at position 110 of TPO is not necessary for the bioactivity of the cytokine.

\section{INTRODUCTION}

Thrombopoietin (TPO) is the primary physiological regulator of platelet production [1-3]. This cytokine has been shown to stimulate megakaryocyte progenitor proliferation and differentiation into mature megakaryocytes (reviewed in [4]). It has recently been demonstrated that TPO acts directly on, and supports, the division of cells more primitive than those committed to the megakaryocyte lineage, indicating a possible use of TPO for activation and expansion of primitive haematopoietic progenitors [5-7]. The ability of recombinant TPO to ameliorate thrombocytopenia in animal models predicts significant therapeutic potential $[8,9]$. TPO, or a related synthetic compound, could therefore be used to enhance the recovery of platelet production in myelosuppressed patients undergoing cancer chemotherapy.

TPO cDNAs have been recently cloned from several species, including man $[1-4,10]$. Sequence analyses revealed that mature human TPO is a 332-residue protein with two domains: a cytokine domain comprising the first $153 \mathrm{~N}$-terminal residues and a 179-residue C-terminal domain containing multiple potential N-linked glycosylation sites. The N-terminal portion of TPO is considered to be the functional domain because it was shown to be sufficient for receptor binding, transduction of a proliferative signal in transfected cells and stimulation of megakaryocytopoiesis both in vitro [1,2] and in vivo [8,9]. This $\mathrm{N}$ terminal sequence of TPO is highly conserved between species and shares $23 \%$ identity with human erythropoietin (EPO), which induces the proliferation and differentiation of immature erythroid cells [11]. In this cytokine domain, allowing for conservative amino acid substitutions, sequence conservation approaches $50 \%$ [12]. The function of the C-terminal domain of TPO, which is not conserved between other members of this cytokine family, remains to be elucidated [13].

The tertiary structure of TPO can be inferred on the basis of sequence homology with other family members. Four conserved cysteine residues are found in the cytokine domain of TPO. Three are conserved in terms of their relative position with reference to human EPO and were found to be important for TPO activity [14-16]. There are three O-glycosylation sites located within the cytokine domain of TPO [15], which could adopt a four $\alpha$-helical structure similar to that determined for growth hormone $(\mathrm{GH})$, leukaemia inhibitory factor, ciliary neurotrophic factor, interleukin 6, granulocyte colony-stimulating factor and the obese protein leptin [17-19]. These proteins are characterized by a similar topological organization of four $\alpha$ helices, with the $\mathrm{A}$ and $\mathrm{D}$ helices forming one antiparallel helical pair and the $\mathrm{B}$ and $\mathrm{C}$ helices forming another. This structure has been proposed for EPO [20] and for the other members of this cytokine family for which structural information is available (reviewed in [21]).

TPO exerts its biological effects through binding to a specific receptor expressed on the cell surface, first identified as the product of the oncogene transduced by the murine myeloproliferative leukaemia (MPL) virus [22-24]. c-Mpl, the TPO receptor, is a member of the growth hormone subfamily of class I cytokine receptors [22,25], which form a homodimeric receptor complex on ligand binding [26,27]. It has been hypothesized that

Abbreviations used: EPO, erythropoietin; GH, growth hormone; TPO, thrombopoietin

1 Present address: INNOTHERA, 10 Avenue Paul-Vaillant Couturier, 94110 Arcueil, France.

2 To whom correspondence should be addressed. 
TPO interacts with at least two identical c-Mpl subunits to generate both proliferation and differentiation signals via the Jak/STAT signalling cascade [28]. TPO probably presents two separate interaction surfaces, one for each receptor subunit. These two surfaces have been mapped from the crystal structure of the complex of GH with two identical receptor subunits [17], and for EPO by using site-directed mutagenesis [26]. Moreover a recent study showed that most of the residues involved in TPO/c-Mpl binding were mapped to helices A and D [29]; however, this study was based on a phage ELISA and no results in terms of TPO bioactivity are available. Thus the functionally important receptor contact sites for TPO have not yet been identified.

In the present study we generated 20 TPO mutants in which the residues chosen for mutation were located mainly in the putative A and D helices. The ability of the soluble TPO mutants to induce the proliferation of factor-dependent c-Mpl-expressing megakaryoblastic M-O7e cells was compared with that of wildtype TPO. The results presented here could help in the determination of a three-dimensional model of TPO, therefore constituting a key step in the design of TPO mimetics.

\section{MATERIALS AND METHODS}

\section{Site-directed mutagenesis}

On the basis of the previously published sequence [1,2] a $0.5 \mathrm{~kb}$ cDNA fragment encoding both the signal peptide and the cytokine domain of TPO was amplified by reverse transcriptasemediated PCR, with human fetal liver mRNA (Clontech, Palo Alto, CA, U.S.A.) as starting material. The PCR product was cloned into the mammalian expression vector pcDNA3 (InVitrogen, Leek, The Netherlands) and sequenced (Genome Express, Grenoble, France) to ascertain the absence of any mutation.

Double-strand mutagenesis was performed with the Transformer ${ }^{\circledR}$ Site-Directed Mutagenesis kit (Clontech) as described previously [30]. Three to ten double-stranded cDNA clones from each mutagenesis reaction were screened by sequencing with the Sequenase Quick-Denature Plasmid Sequencing kit (Amersham, Les Ulis, France) and $\left[\alpha^{-33} \mathrm{P}\right] \mathrm{dATP}$ (Amersham). Subsequently, the entire coding sequence of each mutant was determined in order to ensure the absence of additional unwanted mutations.

\section{Expression of wild-type and mutated TPO}

HEK293 cells, which do not express TPO, were grown in minimum essential medium (Gibco-BRL, Cergy, France) supplemented with $10 \%$ (v/v) fetal calf serum, $2 \mathrm{mM}$ glutamine and $100 \mathrm{i} . \mathrm{u} . / \mathrm{ml}$ penicillin/streptomycin, at $37^{\circ} \mathrm{C}$. One day before transfection, cells were seeded at a density of $3 \times 10^{6}$ per $56 \mathrm{~cm}^{2}$ dish. Wild-type and mutated TPO cDNA species were transfected into HEK293 cells by the calcium phosphate precipitation method [31]. To ensure stable expression, G418 (Gibco-BRL) was added to the culture medium $48 \mathrm{~h}$ after the transfection, at a concentration of $1 \mathrm{mg} / \mathrm{ml}$. After 2-3 weeks of selection, growing clones were isolated and transferred to 96-well plates. These clones were screened for TPO production and the producing clones were expanded.

\section{Quantification of recombinant TPO}

Transfected HEK293 cells were grown for 48-72 h in serum-free minimum essential medium, after which the culture medium was collected, centrifuged at $8400 \mathrm{~g}$ for $5 \mathrm{~min}$, concentrated 10-20fold in microconcentrators (Centricon 10, Amicon, Beverly, MA,
A

\section{WT TPO(ng)}

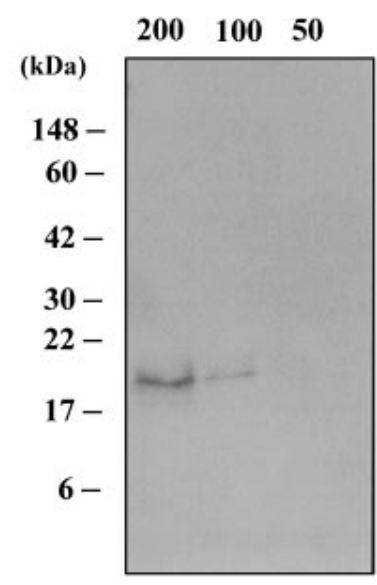

B

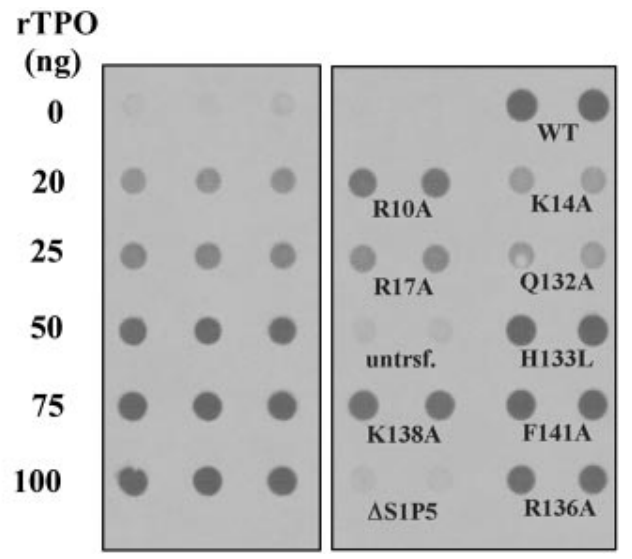

Figure 1 Western blot analysis and quantification of recombinant TPO

(A) Western blot detection of wild-type recombinant TPO. Increasing amounts of TPO were subjected to electrophoresis in $16 \%$ (w/v) polyacrylamide gel under reducing conditions and blotted on a Hybond ${ }^{\mathbb{R}}$ ECL ${ }^{\circledR}$ nitrocellulose membrane. TPO was detected with a rabbit polyclonal antibody $(20 \mu \mathrm{g} / \mathrm{ml})$, a horseradish peroxidase-conjugated anti-rabbit polyclonal antibody and the enhanced chemiluminescence detection kit as described in the Materials and methods section. The molecular masses of protein standards (MultiMark ${ }^{\text {(ind }}$ standard, NOVEX, SanDiego) are indicated at the left. (B) Dot-blot quantification of recombinant wild-type and mutated TPO. Left panel: triplicates of increasing amounts of purified recombinant human TPO used to construct a calibration curve for the quantification experiment; right panel: duplicates of concentrated culture supernatants from cells expressing wild-type or mutated TPO. Purified recombinant human TPO and culture supernatants were spotted on the same Hybond ${ }^{\mathbb{R}} \mathrm{ECL}^{\circledR}$ nitrocellulose membrane. TPO was detected with a rabbit polyclonal antibody, a horseradish peroxidase-conjugated anti-rabbit polyclonal antibody and the enhanced chemiluminescence detection kit as described in the Materials and methods section. The experiment shown is representative of three similar assays.

U.S.A.) and sterilized by filtration. For the quantification of recombinant TPO an immunoassay procedure was employed, with a purified rabbit polyclonal antibody directed against the peptide sequence QLPPQGRTTAHKDP corresponding to residues 111-124 of mature human TPO. Western blot experiments performed with this antibody gave a single band corresponding to TPO (Figure 1A). For quantification experiments (Figure 1B), concentrated culture supernatants were applied with a Bio-Dot ${ }^{\circledR}$ apparatus (Bio-Rad, Hercules, CA, U.S.A.) to a Hybond ${ }^{\circledR}$ ECL $^{\circledR}$ nitrocellulose membrane (Amersham) pre-wetted in TBS $(20 \mathrm{mM}$ Tris $/ \mathrm{HCl} / 140 \mathrm{mM} \mathrm{NaCl})$. After passive filtration of the antigen solutions, the membrane was incubated overnight 
at $4{ }^{\circ} \mathrm{C}$ in a blocking solution $[20 \mathrm{mM}$ Tris $/ \mathrm{HCl}(\mathrm{pH} \mathrm{7.5)/}$ $140 \mathrm{mM} \mathrm{NaCl} / 5 \%$ (w/v) non-fat dried milk]. The membrane was then incubated for $1 \mathrm{~h}$ at room temperature in blocking solution containing the polyclonal antibody directed against the TPO-sequence-derived peptide. After three washes in TTBS [20 mM Tris $/ \mathrm{HCl} / 140 \mathrm{mM} \mathrm{NaCl} / 0.05 \%$ (v/v) Tween 20], the membrane was incubated for $45 \mathrm{~min}$ at room temperature in blocking solution containing a horseradish peroxidase-conjugated goat anti-rabbit polyclonal antibody (Immunotech, Marseille, France). The TPO/antibodies complex was then revealed by using an enhanced chemiluminescence detection kit (Amersham), the membrane was exposed to Hyperfilm, and the signal was quantified with a densitometer apparatus (Molecular Dynamics, Sunnyvale, CA, U.S.A.). Purified recombinant human TPO (PeproTech, Rocky Hill, NJ, U.S.A.) was used to construct a calibration curve for each quantification experiment (Figure 1B, left panel). TPO levels measured by this method correlated well with those determined by an ELISA assay developed in the laboratory (results not shown).

\section{Proliferation assays}

Concentration-dependent proliferation activities of wild-type and mutated TPO were assayed in vitro with the M-07e (human megakaryoblastic leukaemia) cell line [32] as previously described [33] except for the following modifications. Exponentially growing $\mathrm{M}-07 \mathrm{e}$ cells were seeded into 96 -well plates at a concentration of $4 \times 10^{4}$ cells per well in $200 \mu \mathrm{l}$ of assay medium [RPMI 1640 with $25 \mathrm{mM}$ Hepes, supplemented with $10 \%(\mathrm{v} / \mathrm{v})$ fetal bovine serum, $2 \mathrm{mM}$ glutamine and 100 i.u./ml penicillin/streptomycin], supplemented with increasing amounts of conditioned medium from HEK293 cells transfected with an expression vector for wild-type or mutated TPO. The plates were incubated for $72 \mathrm{~h}$ at $37^{\circ} \mathrm{C}$ and $1 \mu \mathrm{Ci}$ per well of $\left[\right.$ methyl $\left.{ }^{3} \mathrm{H}\right]$ thymidine added for $6 \mathrm{~h}$. The cells were then harvested and radioactivity incorporation was determined by liquid-scintillation counting with a Tri-Carb 4640 counter (United Technologies Packard, Downers Grove, IL, U.S.A.). For each TPO mutant the proliferation assays were performed three times, each in duplicate. Concentrationresponse curves, $E_{\max }$ and $\mathrm{EC}_{50}$ values were analysed with the program ORIGIN (Microcal, Northampton, MA, U.S.A.).

\section{RESULTS AND DISCUSSION}

We designed 20 TPO mutants with the information recently published on other four-helix-bundle proteins such as EPO [20,26,34,35], prolactin [36], GH [17] and the obese protein leptin [19]. In a mutagenesis study of EPO, Wen et al. [35] showed that most of the functionally important receptor contact sites were localized on the predicted $\alpha$-helices A and D; similar observations were reported for the $\mathrm{GH} / \mathrm{GH}-$ receptor complex [17], for granulocyte/macrophage colony-stimulating factor [37] and for interleukin 2 [38]. A recent study, based on a TPO phage ELISA, indicated that most of the TPO residues involved in c-Mpl binding were located in helices $\mathrm{A}$ and $\mathrm{D}$ and a loop region between helices A and B [29].

Because the $\alpha$-helices of these proteins are amphiphilic, it is probable that they pack together through their hydrophobic surfaces, which together with the disulphide bonds ensures structural stability. The biologically relevant contact sites are likely to be localized on the hydrophilic side of these molecules, as demonstrated for the solved crystal structure of the complex of GH with two receptor subunits [17] in which the hydrophilic residues of the growth factor's $\alpha$-helices constitute the receptor interaction sites.
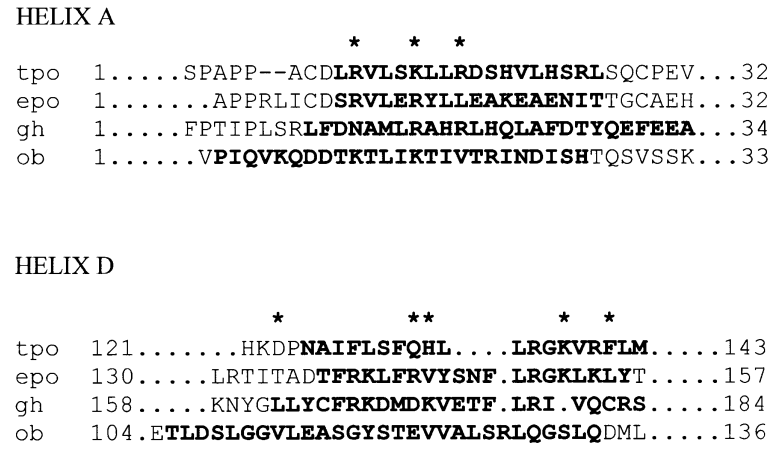

Figure 2 Comparison of primary sequences for various members of the cytokine family

The analysis was restricted to cytokine residues located in the first and the fourth $\alpha$-helices and their adjoining regions. Cytokine residues were aligned by the Clustal method by using the program MEGALIGN (DNAStar, Madison, WI, U.S.A.). Each sequence is numbered, starting with the first residue after the secretory signal cleavage site. Residues in $\alpha$-helices are indicated in bold. The mutated TPO residues for which a significant decrease in potency was observed are indicated by stars. Abbreviations: tpo, TPO; epo, EPO; gh, GH; ob, obese protein leptin.

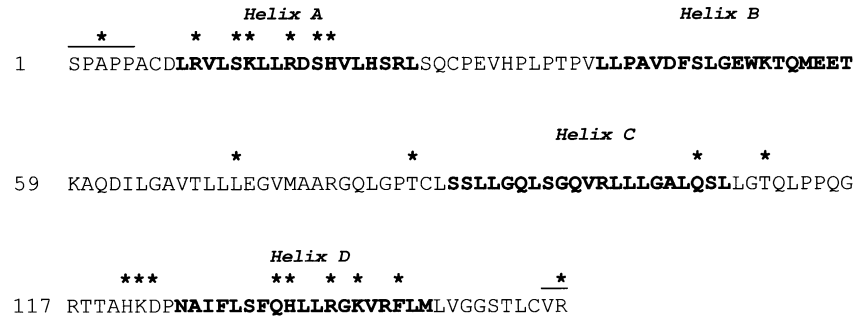

Figure 3 Schematic representation of the primary structure of TPO

The localization of the four putative $\alpha$-helices of TPO is indicated in bold, in accordance with [29]. The mutated residues are indicated by stars. The bars represent the position of the deletions referred to in the Results and discussion section.

Despite the high degree of similarity between TPO and EPO, primary sequence comparison of the $\mathrm{A}$ and $\mathrm{D}$ helices revealed several significant differences (Figure 2). We hypothesized that residues shown to be important for EPO activity [35] and conserved in TPO (i.e. Lys ${ }^{14}$ and Lys ${ }^{138}$ ) should also be involved in receptor binding, whereas hydrophilic residues not conserved in EPO could be critical for the specificity of the TPO/c-Mpl recognition (i.e. $\mathrm{Arg}^{17}$ and $\mathrm{His}^{133}$ ). We therefore focused our analysis on most of the hydrophilic residues of $\mathrm{A}$ and $\mathrm{D}$ helices as well as some amino acids adjoining these regions.

The positions of the mutated residues in TPO are shown in Figure 3. Wild-type and mutated TPOs were expressed in HEK293 human cells and analysed for their ability to sustain the proliferation of TPO-responsive M-O7e megakaryoblast cell line [32]. This human cell line, which constitutively expresses c-Mpl and other megakaryocyte markers [39], was chosen to avoid any species differences between TPO and its receptor in view of the differences reported for EPO/EPO receptor [35]. In addition, the M-O7e cell line was also chosen because it responds strongly to TPO but not to EPO, employing the same signal transduction pathway as megakaryocytes, with the activation of Jak2 and STAT5 [40].

When stimulated by wild-type TPO, M-O7e cell proliferation was concentration-dependent and saturable (Figure 4). Table 1 

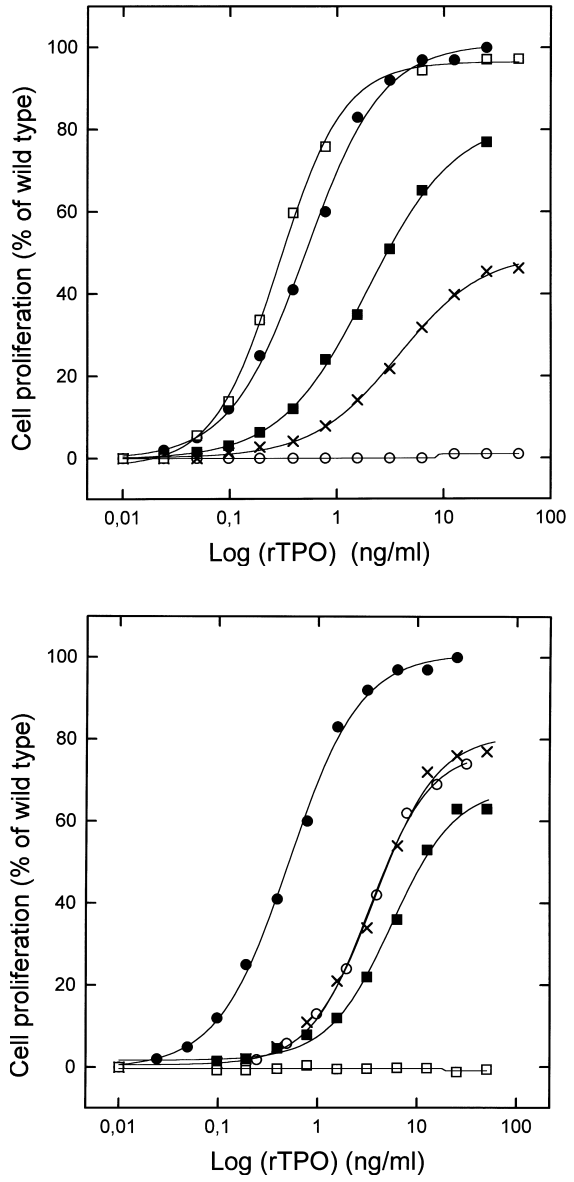

Figure 4 Effect of recombinant wild-type and mutated TPO proteins on M07e cell proliferation

Upper panel: concentration-response curves of wild-type TPO $(\mathbf{O})$ and TPO mutants located on helix A: R10A $(O)$, K14A $(\times)$, R17A $(\boldsymbol{\square})$ and S19A $(\square)$. Lower panel: Concentration-response curves of wild-type TPO $(\mathbf{O})$ and TPO mutants located on helix D: Q132A (O), H133L (X), F141A (ם) and K138A ( $\square$ ). The ability of conditioned medium from HEK293 cells expressing wild-type or mutated TPO to induce proliferation of M-07e cells was measured by the incorporation of $\left[{ }^{3} \mathrm{H}\right]$ thymidine into DNA, as described in the Materials and methods section. Each point is the average of duplicate determinations. Results, representative of three separate experiments, are given with S.E.M. values in Table $1 ; 100 \%$ represents the maximal proliferating activity obtained with wild-type TPO for each experiment.

presents specific bioactivity data on all of the mutants, compared with wild-type TPO.

\section{Effects of $\mathrm{N}$ - and C-terminal deletions}

Two deletion mutants were constructed, $\Delta \operatorname{Ser}^{1}$ Pro $^{5}$ and $\Delta \mathrm{Val}^{152} \mathrm{Arg}^{153}$, to study the involvement of the $\mathrm{N}$ - and C-terminal residues in TPO/c-Mpl interaction. The deleted residues were chosen such that the disulphide bond located between $\mathrm{Cys}^{7}$ and $\mathrm{Cys}^{151}$ of TPO was conserved [15] and tertiary structure was maintained.

No N-terminal deleted TPO mutant was detected in the supernatant of transfected cells (Figure 1B). Although our study did not show whether this mutant was synthesized, it is possible that the location of the deletion, downstream from the signal peptide, prevents its secretion from the cells. As a corollary to this, it has been reported that deletion of the corresponding region in EPO led to lower yields of secreted protein in comparison with the wild type, probably owing to impaired

\section{Table 1 Proliferation data for wild-type TPO and TPO mutants}

Values shown represent both $E_{\max }$ and $\mathrm{EC}_{50}$ ratios between mutant and simultaneously tested wild-type TPO, and are means \pm S.E.M. for two to five independent determinations. $E_{\max }$ and $\mathrm{EC}_{50}$ were measured by non-linear regression as described in the Materials and methods section. ${ }^{\star} P<0.05,{ }^{\star \star} P<0.01$ compared with the wild type (Student's $t$ test). Abbreviation: n.e., not expressed

\begin{tabular}{llc}
\hline TP0 variant & $E_{\max }$ for mutant/ $E_{\max }$ for wild type & $\begin{array}{l}\mathrm{EC}_{50} \text { for mutant/EC } \\
\text { for wild type }\end{array}$ \\
\hline Wild type & 1.00 & 1.00 \\
$\Delta$ S1P5 & n.e. & n.e. \\
$\Delta$ V152R153 & $1.08 \pm 0.07$ & $1.58 \pm 0.15^{*}$ \\
R10A & Inactive & Inactive \\
S13A & $0.96 \pm 0.02$ & $1.57 \pm 0.41$ \\
K14A & $0.41 \pm 0.06^{* *}$ & $8.38 \pm 1.71^{*}$ \\
R17A & $0.70 \pm 0.02^{*}$ & $3.62 \pm 0.40^{*}$ \\
S19A & $0.96 \pm 0.05$ & $0.48 \pm 0.06^{*}$ \\
H20L & $1.00 \pm 0.12$ & $1.14 \pm 0.05$ \\
L71A & $0.81 \pm 0.02$ & $1.33 \pm 0.10$ \\
T84A & $0.71 \pm 0.02$ & $5.43 \pm 0.34^{* *}$ \\
Q105A & $0.99 \pm 0.16$ & $12.06 \pm 2.84^{* *}$ \\
T110A & $0.93 \pm 0.02$ & $1.29 \pm 0.17$ \\
H121L & $0.83 \pm 0.02$ & $1.28 \pm 0.08$ \\
K122A & $0.96 \pm 0.06$ & $0.87 \pm 0.06$ \\
D123N & $0.93 \pm 0.12$ & $5.24 \pm 0.25^{* *}$ \\
Q132A & $0.88 \pm 0.01$ & $9.83 \pm 2.25^{*}$ \\
H133L & $0.88 \pm 0.02$ & $10.47 \pm 0.16^{* *}$ \\
R136A & $0.64 \pm 0.07$ & $2.53 \pm 0.73$ \\
K138A & Inactive & Inactive \\
F141A & $0.69 \pm 0.01$ & $7.62 \pm 0.95^{* *}$ \\
& & \\
\hline
\end{tabular}

cleavage of the propeptide [20]. In contrast, the C-terminal TPO deletion mutant $\left(\Delta \mathrm{Val}^{152} \mathrm{Arg}^{153}\right)$ was readily secreted from the cells and was biologically active (Table 1). This indicates that the two non-helical C-terminal residues of the cytokine domain are not important for its binding to $\mathrm{c}-\mathrm{Mpl}$, in agreement with results reported for EPO, for which the deletion of the four last amino acids did not modify the specific activity of the protein [20].

\section{Effects of single mutations on helix A}

Within the predicted helix A, the TPO mutants that mostly affected the proliferative responses of $\mathrm{M}-\mathrm{O} 7 \mathrm{e}$ cells were located at positions 10 and 14 and to a smaller extent at position 17 (Table 1). Replacement of $\mathrm{Arg}^{10}$ by Ala resulted in a mutated TPO unable to promote M-O7e proliferation at concentrations of up to $50 \mathrm{ng} / \mathrm{ml}$, whereas wild-type TPO showed its maximum efficacy at a concentration of $5 \mathrm{ng} / \mathrm{ml}$ (Figure 4 and Table 1). The mutation of this residue by Ala was recently reported to have no significant effect on TPO/c-Mpl binding [29]. These results suggest that the R10A mutant can bind efficiently to c$\mathrm{Mpl}$ but is unable to effect receptor dimerization and, consequently, signal transduction. Interestingly, the same mutation was without effect in EPO [26,35], suggesting that $\operatorname{Arg}^{10}$ of predicted helix A contributes specifically to the function of TPO. An equivalent residue $\left(\mathrm{Asn}^{12}\right)$ located at a similar position in $\mathrm{GH}$ (Figure 2) was found to interact with the GH receptor [17].

Replacement of Lys ${ }^{14}$ by Ala resulted in a marked attenuation of $\mathrm{M}-\mathrm{O} 7 \mathrm{e}$ proliferation (Figure 4 and Table 1) ( $E_{\max }$ for $\mathrm{K} 14 \mathrm{~A} / E_{\max }$ for wild type $=0.41$ ), accompanied by a significant decrease in TPO potency ( $\mathrm{EC}_{50}$ for wild type, $0.56 \mathrm{ng} / \mathrm{ml} ; \mathrm{EC}_{50}$ for K14A, $4.69 \mathrm{ng} / \mathrm{ml}$ ). Such decreases in bioactivity correlate well with the decrease in c-Mpl binding observed for this mutant [29]. In EPO, for which the corresponding residue is Arg instead 
A.

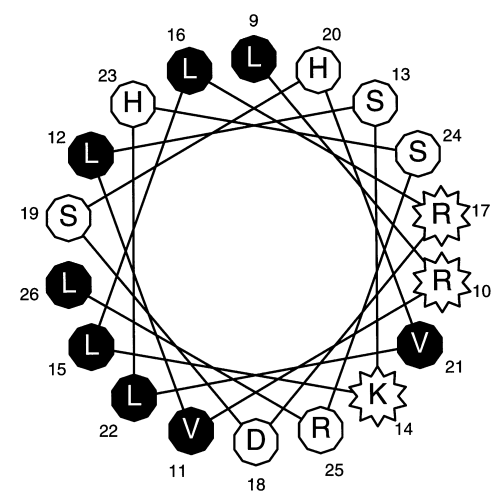

B.

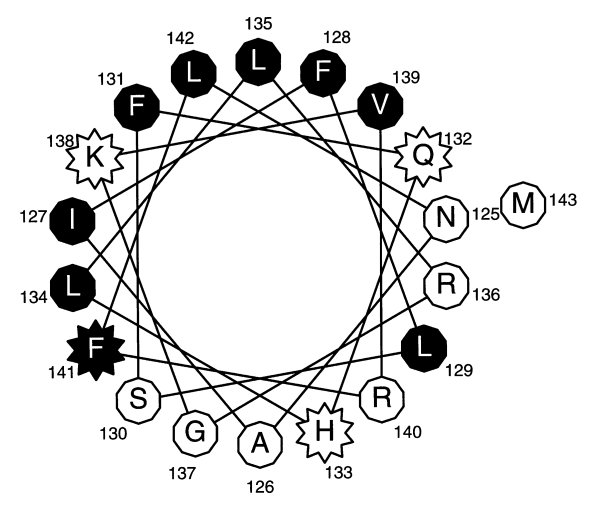

Figure 5 Helical wheel projections of the putative helices $A(A)$ and $D(B)$ of TPO

The projections are viewed from the $\mathrm{NH}_{2}$ end of each helix. The hydrophobic residues are indicated by filled circles. The mutated residues for which a significant decrease in potency was observed are represented by stars.

of Lys, a similar decrease in proliferative activity was observed when mutated to Ala [26,35]. This suggests a similar pattern of interaction between the positively charged residue at position 14 of these two cytokines and their respective receptors.

Mutation R17A resulted in a $30 \%$ impairment in the maximum proliferative response of TPO (Figure 4 and Table 1), accompanied by a 3.6-fold decrease in TPO potency $\left(\mathrm{EC}_{50}\right.$ for wild type, $0.56 \mathrm{ng} / \mathrm{ml}$; $\mathrm{EC}_{50}$ for R17A, $2.03 \mathrm{ng} / \mathrm{ml}$ ). The corresponding residue in EPO is Leu, which was shown not to be involved in $\mathrm{EPO} /$ receptor interaction [26,35]. It is possible that $\operatorname{Arg}^{17}$ contributes to the specific $\mathrm{TPO} / \mathrm{c}-\mathrm{Mpl}$ interaction, probably owing to the longer side chain and/or the positive charge.

The three residues of helix A for which mutation affects TPO bioactivity form a cluster of positively charged residues located on the same side of the helix (Figure 5A). Their sensitivity to mutation suggests that they interact directly with the receptor, the most important being $\mathrm{Arg}^{10}$ and $\mathrm{Lys}^{14}$ of TPO. Two basic residues (Lys ${ }^{11}$ and Lys $^{15}$ ) located at a similar position in the obese protein leptin (Figure 2) have been recently shown to be exposed [19], and the side chains of three equivalent residues located on helix A of GH (Asn ${ }^{12}, \operatorname{Arg}^{16}$ and $\operatorname{Arg}^{19}$ ) were found to be involved at the $\mathrm{GH} / \mathrm{GH}$ receptor interface [17].

When the three other sites predicted to be on the opposite face of helix $\mathrm{A}\left(\mathrm{Ser}^{13}, \mathrm{Ser}^{19}\right.$ and $\mathrm{His}^{20}$ ) were mutated, normal bioactivity was observed (Table 1) (Figure 5A). This side of the helix is probably not exposed to the receptor and would thus face the hydrophobic sites of other TPO helices forming the buried core of the cytokine.

\section{Effects of single mutations between helices A and D}

Four mutations were introduced between helices $A$ and D of TPO (Figure 3). Two (L71A and T110A) induced a response similar to that of wild-type TPO, suggesting that they are not critical for function (Table 1). The Thr residue at position 110 is a site of O-glycosylation [15], so these results demonstrate that it is not necessary for TPO function.

Mutation of $\mathrm{Thr}^{84}$ and $\mathrm{Gln}^{105}$ to Ala resulted in significant 5.4- and 12.1-fold potency decreases respectively $\left(\mathrm{EC}_{50}\right.$ for wild type, $0.56 \mathrm{ng} / \mathrm{ml} ; \mathrm{EC}_{50}$ for T84A, $3.04 \mathrm{ng} / \mathrm{ml} ; \mathrm{EC}_{50}$ for Q105A, $6.75 \mathrm{ng} / \mathrm{ml}$ ) with the maximum proliferative response remaining similar to that of the wild type (Table 1). In the absence of structural data, it is difficult to conclude whether the increased $\mathrm{EC}_{50}$ values observed were due to the destabilization of intramolecular bonds, or to intermolecular TPO/c-Mpl interactions. Nevertheless the fact that these two mutants induced $\mathrm{M}-\mathrm{O} 7 \mathrm{e}$ proliferation with comparable efficiencies to that of wild-type TPO suggests that the overall conformation of the protein is conserved.

\section{Effects of single mutations on helix D}

Five mutants were constructed in helix D of TPO and three in its upstream adjoining region (Figure 3 and Table 1). Three mutants (H121L, K122A and R136A) induced a response similar to that of wild-type TPO (Table 1).

$\mathrm{Asp}^{123}$ is functionally important because, when mutated to Asn, a limited but significant decrease in TPO potency was observed $\left(\mathrm{EC}_{50}\right.$ for wild type, $0.56 \mathrm{ng} / \mathrm{ml} ; \mathrm{EC}_{50}$ for $\mathrm{D} 132 \mathrm{~N}$, $2.93 \mathrm{ng} / \mathrm{ml}$ ), with a maximum proliferative response similar to that of the wild type (Table 1). Asp ${ }^{123}$ is thought to be located in the CD loop of TPO, in the adjoining region of helix D. An Asp residue located in the corresponding region of $\mathrm{EPO}\left(\mathrm{Asp}^{136}\right)$, was shown not to be involved in the bioactivity of the cytokine [26]. Nevertheless, with loop CD being much shorter in TPO than in EPO, its conformation and mode of interaction with c-Mpl might be different from those for the same loop in EPO.

Three other residues, located in helix D, seemed to be important for TPO activity (His ${ }^{133}$, Lys ${ }^{138}$ and Phe ${ }^{141}$ ). The K138A mutant was particularly notable in that it produced no measurable proliferation activity at a concentration up to $50 \mathrm{ng} / \mathrm{ml}$. This effect seems to be due to an impairment of the mutant's binding of c-Mpl, as shown recently with the use of a phage ELISA [29], even if it cannot be excluded in the latter case that linkage to gene III protein of the phage leads to conformational changes. This is similar to EPO, where the corresponding K152A mutation led to a 33-fold decrease in proliferation [26]. Because this residue has been postulated to be involved in the initial EPO receptorbinding event, one could hypothesize a similar role for $\mathrm{Lys}^{138}$ of TPO.

The mutation of $\mathrm{His}^{133}$ to Leu resulted in a decrease in potency by less than 10 -fold $\left(\mathrm{EC}_{50}\right.$ for wild type, $0.56 \mathrm{ng} / \mathrm{ml} ; \mathrm{EC}_{50}$ for $\mathrm{H} 133 \mathrm{~L}, 5.86 \mathrm{ng} / \mathrm{ml})$. The helical wheel projection of helix D shows that this polar residue is found in a hydrophilic environment, surrounded by $\operatorname{Ser}^{130}$ and $\operatorname{Arg}^{140}$ (Figure 5B). This suggests an accessibility of His $^{133}$ to solvent and thus a direct interaction between its side chain and the c-Mpl-binding site.

Mutation of $\mathrm{Phe}^{141}$ to Ala resulted in a $30 \%$ decrease in $\mathrm{M}$ O7e proliferation (Figure 4 and Table 1), accompanied by a 7.6-fold decrease in TPO potency $\left(\mathrm{EC}_{50}\right.$ for wild type, $0.56 \mathrm{ng} / \mathrm{ml}$; $\mathrm{EC}_{50}$ for F141A, $\left.4.27 \mathrm{ng} / \mathrm{ml}\right)$. The localization of $\mathrm{Phe}^{141}$ on the 
same side of helix D as His ${ }^{133}$ and Lys ${ }^{138}$ (Figure 5B) suggests a direct interaction with the receptor through its aromatic side chain in stacking interactions with other aromatic residues of cMpl.

When $\mathrm{Gln}^{132}$ was mutated to Ala, a significant decrease in TPO potency $\left(\mathrm{EC}_{50}\right.$ for wild type, $0.56 \mathrm{ng} / \mathrm{ml} ; \mathrm{EC}_{50}$ for Q132A, $5.50 \mathrm{ng} / \mathrm{ml}$ ) was observed, probably owing to the destabilization of an intramolecular bond. The topological representation of helix D shows (Figure 5B) that residue $\mathrm{Gln}^{132}$ is located opposite to $\mathrm{His}^{133}$, Phe ${ }^{141}$ and $\mathrm{Lys}^{138}$, which were proposed to be exposed to side chains of the receptor. Gln ${ }^{132}$ is also surrounded by hydrophobic residues $\left(\mathrm{Phe}^{128}, \mathrm{Leu}^{129}, \mathrm{Leu}^{135}\right.$ and $\mathrm{Val}^{139}$ ), probably facing the compact core of the cytokine, and by $\mathrm{Arg}^{136}$ residue, which is not involved in TPO bioactivity. It was recently demonstrated that the mutation of $\mathrm{Gln}^{132}$ to Ala was without effect on TPO/c-Mpl binding [29], indicating that this residue is probably not exposed to the receptor. The side chain of $\mathrm{Asp}^{132}$ is likely to be inaccessible to solvent and involved in a direct and structurally important intramolecular interaction with a carboxylic residue of TPO. Mutation of $\mathrm{Gln}^{132}$ to Ala probably induces the destabilization of this core steric interaction, leading to the observed decrease in TPO efficacy.

\section{Conclusion}

Ten residues on the TPO molecule have been demonstrated to be important for its bioactivity. Three of these are located in helix A of the protein and four in helix D, in good agreement with findings previously described for other cytokines such as EPO $[26,35]$ and $\mathrm{GH}[17,41]$. Our results on the functionally important residues of TPO are largely in agreement with those recently reported for the TPO residues involved in c-Mpl binding [29]. However, several mutations seem to have greater effects in terms of M-O7e cell proliferation than in the reported phage ELISA binding assay [29]. This is particularly striking for the R10A mutant, which completely lacked proliferative activity on M-O7e cells, whereas it was reported to have no significant effect in terms of binding to the c-Mpl. Such a discrepancy seems to indicate that $\mathrm{Arg}^{10}$ of TPO is a critical determinant for the c-Mpl dimerization needed for signal pathway induction.

This study gives a functional basis for the construction of a three-dimensional model of TPO and, in view of the therapeutic potential of this cytokine, might facilitate the rational design of TPO mimetics. These results might also help to identify key recognition determinants of $\mathrm{c}-\mathrm{Mpl}$.

We thank D. Patinet for secretarial assistance, Dr. G. Georges, Dr. B. Cornet and Dr. V. Saudeck for valuable discussions, and Dr. S. O'Connor and Dr. D. Graham for advice and support.

\section{REFERENCES}

1 Bartley, T. D., Bogenberger, J., Hunt, P., Li, Y. S., Lu, H. S., Martin, F., Chang, M. S., Samal, B., Nichol, J. L., Swift, S. et al. (1994) Cell 77, 1117-1124

2 De Sauvage, F. J., Hass, P. E., Spencer, S. D., Malloy, B. E., Gurney, A. L., Spencer, S. A., Darbonne, W. C., Henzel, W. J., Wong, S. C. et al. (1994) Nature (London) 369, 533-538

3 Lok, S., Kaushansky, K., Holly, R. D., Kuljper, R. D., Lofton-Day, C. E., Oort, P. J., Grant, F. J., Helpel, M. D., Burkhead, S. K., Kramer, J. M. et al. (1994) Nature (London) 369, 565-568

4 Kaushansky, K. (1995) Blood 86, 419-431
5 Ku, H., Hirayama, F., Kato, T., Miyazaki, H., Aritomi, M., Ota, Y., D-Andrea, A. D., Lyman, S. D. and Ogawa, M. (1996) Blood 88, 4124-4131

6 Sitnicka, E., Lin, N., Priestley, G. V., Fox, N., Broudy, V. C., Wolf, N. S. and Kaushansky, K. (1996) Blood 87, 4998-5005

7 Young, J. C., Bruno, E., Luens, K. M., Wu, S., Backer, M. and Murray, L. J. (1996) Blood 88, 1619-1631

8 Ulrich, T. R., del Castillo, J., Senaldi, G., Kinstler, 0., Yin, S., Kaufman, S., Tarpley, J., Choi, E., Kirley, T., Hunt, P. and Sheridan, W. (1996) Blood 87, 5006-5015

9 Farese, A. M., Hunt, P., Boone, T. and MacVittie, T. (1995) Blood 86, 54-59

10 Kaushansky, K., Lok, S., Holly, R. D., Broudy, V. C., Lin, N., Bailey, M. C., Forstrom, J. W., Buddle, M. M., Oort, P. J., Hagen, F. S. et al. (1994) Nature (London) $\mathbf{3 6 9}$ 568-571

11 Jacobs, K., Shoemaker, C., Rudersdorf, R., Neill, S. D., Kaufman, R. J., Mufson, A., Seehra, J., Jones, S. S., Hewick, R., Fritsch, E. F. et al. (1985) Nature (London) 313 806-810

12 Lok, S. and Foster, D. C. (1994) Stem Cells 12, 586-598

13 Hoshi, S., Yoshitomi, H., Komatsu, N., Yoshitake, S. and Masayuki, 0. (1997) Biochem. Biophys. Res. Commun. 231, 823-826

14 Wada, T., Nagata, Y., Nagahisa, H., Okutomi, K., Ha, S. H., Ohnuki, T., Kanaya, T., Matsumura, M. and Todokoro, K. (1995) Biochem. Biophys. Res. Commun. 213, 1091-1098

15 Hoffman, R. C., Anderson, H., Walker, K., Krakover, J. D., Patel, S., Stamm, M. R. and Osborn, S. G. (1996) Biochemistry 35, 14849-14861

16 Wang, F. F., Kung, C. H. and Goldwasser, E. (1983) Endocrinology (Baltimore) 116 2286-2292

17 De Vos, A. M., Ultsch, M. and Kossiakoff, A. A. (1992) Science 255, 306-312

18 Robinson, R. C., Grey, L. M., Staunton, D., Vankelecom, H., Vernallis, A. B., Moreau, J. F., Stuart, D. I., Heath, J. K. and Jones, E. Y. (1994) Cell 77, 1101-1116

19 Zhang, F., Basinski, M. B., Beals, J. M., Briggs, S. L., Churgay, L. M., Clawson, D. K., DiMarchi, R. D., Furman, T. C., Hale, J. E., Hsiung, H. M. et al. (1997) Nature (London) 387, 206-209

20 Boissel, J. P., Lee, W. R., Presnell, S. R., Cohen, F. E. and Bunn, H. F. (1993) J. Biol. Chem. 268, 15983-15993

21 Nicola, N. A. (1995) Ann. N.Y. Acad. Sci. 766, 253-262

22 Vigon, I., Mornon, J. P., Cocault, L., Mitjavila, M. T., Tambourin, P., Gisselbrecht, S. and Souyri, M. (1992) Proc. Natl. Acad. Sci. U.S.A. 89, 5640-5644

23 Skoda, R. C., Seldin, D. C., Chiang, M. K., Peichel, C. L., Vogt, T. F. and Leder, P. (1993) EMBO J. 12, 2645-2653

24 Vigon, I., Florino, C., Fichelson, S., Guenet, J. L., Mattei, M. G., Souyri, M., Cosman, D. and Gisselebrecht, S. (1993) Oncogene 8, 2607-2611

25 Souyri, M., Vigon, I., Penciolelli, J. F., Heard, J. M., Tambourin, P. and Wendling, F. (1990) Cell 63, 1137-1147

26 Matthews, D. J., Topping, R. S., Cass, R. T. and Giebel, L. B. (1996) Proc. Natl. Acad. Sci. U.S.A. 93, 9471-9476

27 Livnah, 0., Stura, E. A., Johnson, D. L., Middleton, S. A., Mulcahy, L. S., Wrighton, N. C., Dower, W. J., Jolliffe, L. K. and Wilson, I. A. (1996) Science 273, 464-471

28 Alexander, W. S., Maurer, A. B., Novak, U. and Harrison-Smith, M. (1996) EMBO J. 15, 6531-6540

29 Pearce, K. H., Potts, B. J., Presta, L. G., Bald, L. N., Fendly, B. M. and Wells, J. A. (1997) J. Biol. Chem. 272, 20595-20602

30 Jagerschmidt, A., Guillaume, N., Goudreau, N., Maigret, B. and Roques, B. P. (1995) Mol. Pharmacol. 48, 783-789

31 Chen, C. and Okayama, H. (1987) Mol. Cell. Biol. 7, 2745-2752

32 Avanzi, G. C., Lista, P., Giovinazzo, B., Miniero, R., Saglio, G., Benetton, G., Coda, R., Cattoretti, G. and Pegoraro, L. (1988) Br. J. Haematol. 69, 359-366

33 McDonald, T. P., Wendling, F., Vainchenker, W., McCarty, J. M., Jorgenson, M. J. and Kaushansky, K. (1995) Blood 85, 292-294

34 Chern, Y., Chung, T. and Sytkowski, A. J. (1991) Eur. J. Biochem. 202, 225-229

35 Wen, D., Boissel, J. P., Showers, M., Ruch, B. C. and Bunn, H. F. (1994) J. Biol. Chem. 269, 22839-22846

36 Goffin, V., Martial, J. A. and Summers, N. L. (1995) Protein Eng. 8, 1215-1231

37 Shanafelt, A. B., Miyajima, A., Kitamura, T. and Kastelein, R. A. (1991) EMBO J. 10, 4105-4112

38 Zurawski, S. M. and Zurawski, G. (1988) EMBO J. 7, 1061-1069

39 Drexler, H. G., Zaborski, M. and Quentmeier, H. (1997) Leukemia 11, 541-551

40 Sasaki, K., Odai, H., Hanazono, Y., Ueno, H., Ogawa, S., Langdon, W. Y., Tanaka, T., Miyagawa, K., Minati, K., Yazaki, Y. and Hirai, H. (1995) Biochem. Biophys. Res. Commun. 216, 338-347

41 Cunningham, B. C. and Wells, J. A. (1989) Science 244, 1081-1085

Received 13 January 1998/30 April 1998; accepted 11 May 1998 